\title{
Surgery in space: the future of robotic telesurgery (Haidegger T, Szandor J, Benyo Z. Surg Endosc 2011; 25(3):681-690)
}

\author{
Jacques Himpens
}

Published online: 20 August 2011

(C) Springer Science+Business Media, LLC 2011

\section{To the Editor}

I read with interest the article published by Haidegger et al. [1] in the March issue of Surgical Endoscopy. They, however, wrongly state that the very first human trials with the Mona robot prototype involved "vascular and gynecologic procedures." In fact, on 3 March 1997, I successfully performed the first two telesurgical laparoscopic cholecystectomies as well as a lysis of adhesions in the Saint-Blasius General Hospital at Dendermonde, Belgium [2]. A vascular anastomosis (an arteriovenous fistula for dialysis) was performed by Dr Marc Bosiers on the same occasion. No gynecologic procedures were performed at that time. The next telesurgical procedures were performed by Dr Guy-Bernard Cadière in Paris 1 year later in May 1998.

\section{References}

1. Haidegger T, Szandor J, Benyo Z (2011) Surgery in space: the future of robotic telesurgery. Surg Endosc 25:681-690

2. Himpens J, Leman G, Cadière GB (1998) Telesurgical laparoscopic cholecystectomy. Surg Endosc 12:1091
J. Himpens $(\bowtie)$

Department of Minimally Invasive and Bariatric Surgery,

Saint-Blasius General Hospital, Dendermonde, Belgium

e-mail: jacques_himpens@hotmail.com 